\title{
TOWARDS AN EVOLUTIONARY DESIGN IN LEBANESE VERNACULAR DWELLINGS
}

\author{
T. HAIDAMOUS \\ PhD Candidate in Design Sciences, IUAV, University of Venice, Italy.
}

\begin{abstract}
Lebanese vernacular architecture may represent the 'un-selfconscious' process, a term nailed by Christopher Alexander. In what follows, I present an understanding of some of the properties of Lebanese vernacular dwellings and demonstrate how their attributes must be selectively transferred to an evolutionary design through our biology of consciousness to create a residential high-rise, Beirut Sustainable Residential Prototype (BSRP), that responds to economical, cultural and social needs in Beirut. Tradition and technology cross-pollinated each other to provide a residential prototype thought of as an extension of nature, thus, as a genetic cultural expression as discussed in evolutionary biologist Richard Dawkin's book; furthermore, this paper will state the methods of intimate integration of renewable energy resources into the fabric of the structures that formulate today's buildings. The research project that will be described in this paper started in 2009 onwards during the master thesis program of Sustainable Architecture - Smart Building and Urban Innovation - at IED (Istituto Europeo di Design) in Torino, Italy, distilling passive strategies learned from Lebanese vernacular architecture and reinterpreting them to provide the future with solutions that interweave naturally the urban fabric with its environment; furthermore, the project intends to promote bioethics and an urgent awareness in the Lebanese construction industry to view buildings as organisms that enhance ecological health and enriches the culture and history of a nation.
\end{abstract}

Keywords: Evolutionary design, Lebanese vernacular architecture, sustainable residential prototype

\section{INTRODUCTION}

The experiment that follows is based upon Alexander's hypothesis [1] of unselfconscious design wherein the form, fitting and adapted to its context is the direct response to the user's needs so it is always a functional one. In the 'unselfconscious' situation, the teaching of handcraft skills is done through demonstration and is usually applicable in primitive societies or vernacular architectural context. In the selfconscious process, design is taught academically through theoretical explanation and explicit formulation. I will henceforth describe the environmental and cultural characteristics of the Lebanese vernacular architecture, considering it as Alexander's unselfconscious design, to project its attributes to the future in a product adapted to modern needs, thus bridging the 'unselfconscious' to adapt with the 'selfconscious'. Although the idea of adaptation may sound simple, yet it demands some further biological understanding where, in that regards, I recurred in the following two paragraphs to two main items, respectively: the neurological basis of design and Ashby's 'adaptive machine' [2] called the Homeostat described in his book, Design for a Brain.

\section{NEUROLOGICAL BASIS OF DESIGN}

The human hunger for information and novelty is related to providing stimulation for the neocortex part of the brain, resulting in a pleasure feeling. Biederman and Vessel [3] explain that there is a boost in the pleasant effects if ever a stimulus is triggered by a great deal of interpretable information; furthermore, the brain has information acquisition mechanisms that reward us for learning about the environment. Even if the new information is not put directly into practical use, there is in, evolutionary terms, adaptive value to its acquisition. Nowadays, our neocortex stimulation hunger is satiated to a great extent by electronic information technology and augmented reality that are gradually disconnecting us from the actual physical world and its natural processes. The more humans 
satisfy the neocortex with technology removed from natural processes, the more the brain is provoking alienation from ecology and natural lifecycle events. This is why the brain must be fed with proper information to simulate designs thought of as an extension of nature, thus as a genetic cultural expression as discussed in evolutionary biologist Richard Dawkin's book, Extended Phenotype [4].

\section{BIOLOGICAL DESIGN: DARWINISM AND HOMEOSTASIS}

The evolution of Lebanese vernacular architecture through centuries may refer to the perception of Darwinism: the notion that refinement in design is achieved through natural selection, where the fittest design is the one that is prevalent and that survives the test of environment and culture. Beirut Sustainable Residential Prototype (BSRP) illustrates Claude Bernard's concept of homeostasis [5]: 'The constancy of the internal environment is the condition for a free and independent life.' Through the evolutionary idea of Lebanese vernacular architecture, one can observe the key traits of every mutation in favour of the inhabitants' comfort, while in homeostasis the designer or the architect can use these traits profitably to emulate a living system, in this case the residential prototype under discussion, capable of adaptation to bioclimatic factors, thus creating Ashby's 'adaptive machine', the Homeostat.

\section{LIWAN HOUSE}

Liger-Belair and Kalayan's 'The Dwelling in Lebanon' [6] presents a comprehensive overview on the evolution and classification of traditional dwellings in Lebanon. Kalayan classification presents five types: the rectangular, the courtyard, the Liwan, the Khan type and the exterior gallery dwellings. In this paper, I will highlight the Liwan type (Fig. 1) as it is the main source of inspiration for BSRP design. The Liwan plan is composed of a Liwan, a central room opened to the exterior by an arc, and flanked by two or more closed rooms on each side of the central room. This spatial organization allows for a shaded and ventilated space for a family gathering during summer, while provides a protected buffer against climatic adversities in winter. The Liwan type social value is explicit in its adaptation to different needs and functions. There exists a combination of two or three units with Liwan to form an $\mathrm{L}$ or a $\mathrm{U}$ shape around an interior space, a courtyard, or a garden. I shall call the terrace in the apartment of my project the Liwan terrace.

\subsection{Liwan terrace: growing own food and biophilic design}

Lebanese vernacular houses may be easily encountered in rural areas in Lebanon. They are surrounded by nature, cultivating a healthy lifestyle where one grows his own food through agriculture. This mountainous landscape of architecture, fruit trees and vegetation still represents a model of sound resource management that we nowadays lack in urban areas where little or almost none of the land investment is dedicated for growing organic food. Alas, the result is a city where most surfaces are impervious, hence rainwater is no more absorbed by the earth and ground water is gradually being lost. In BSRP, I showed that a part of spatial organization is dedicated for growing organic food, and that even in high-rise buildings agriculture may be conceived as an essential element, provided they are located in adequate spaces on the terrace (Fig. 2) and preferably oriented towards the south. With the visual perception of the greenery in the Liwan terrace, the apartment advocates biophilic design and the occupant's affinity to nature may be quenched to a great extent by the presence of vegetation and fruit trees in their house, echoing the design of Lebanese vernacular houses in the rural areas.

\section{SELF-SHADED MORPHOLOGY}

The tetrahedral shape of the tilted roof in the Central Hall house has been taken as an attribute to shape the south facade, in which the morphology interacts with the sun's circulation. This attribute merges with another characteristic of the Liwan House that is the shadow casted on the Liwan from 

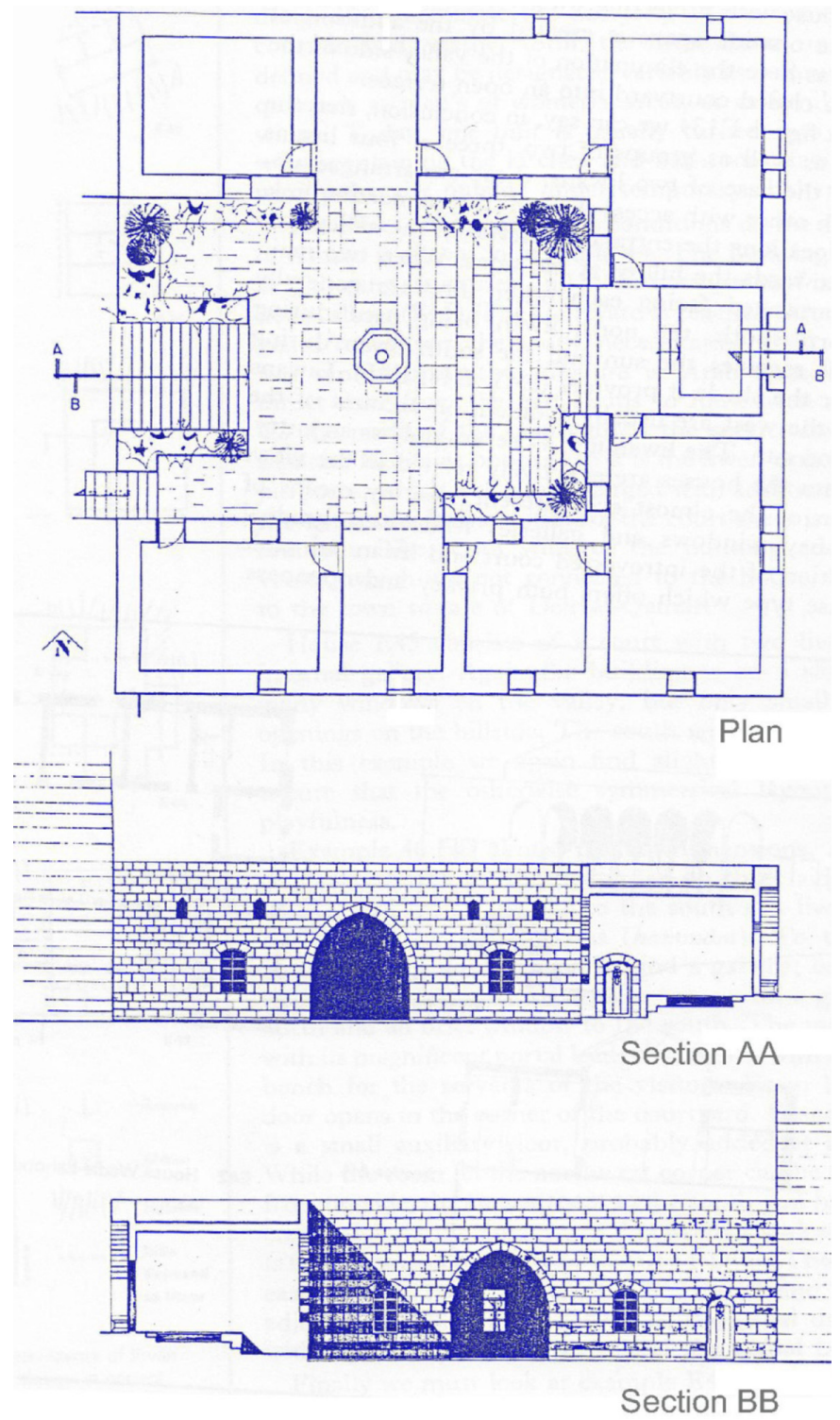

Figure 1: Example of Liwan type.

adjacent volumes of the house, thus, the pattern of shadows and light on the facade of the residential prototype that evolved from merging genes of two different typologies of Lebanese houses. The shadow analysis of the south facade shows that the terraces are always self-shaded in summertime and this helps in reducing energy consumption for the cooling loads (Fig. 3). The term self-shaded was deliberately used to point out that due to specific slopes' angles created by the terraces' limits, any terrace is being protected by the upper one, and the upper one by the one above it until all terraces are self-protected. In winter, the same terraces receive direct solar radiation and that favours in reducing heating demands. 

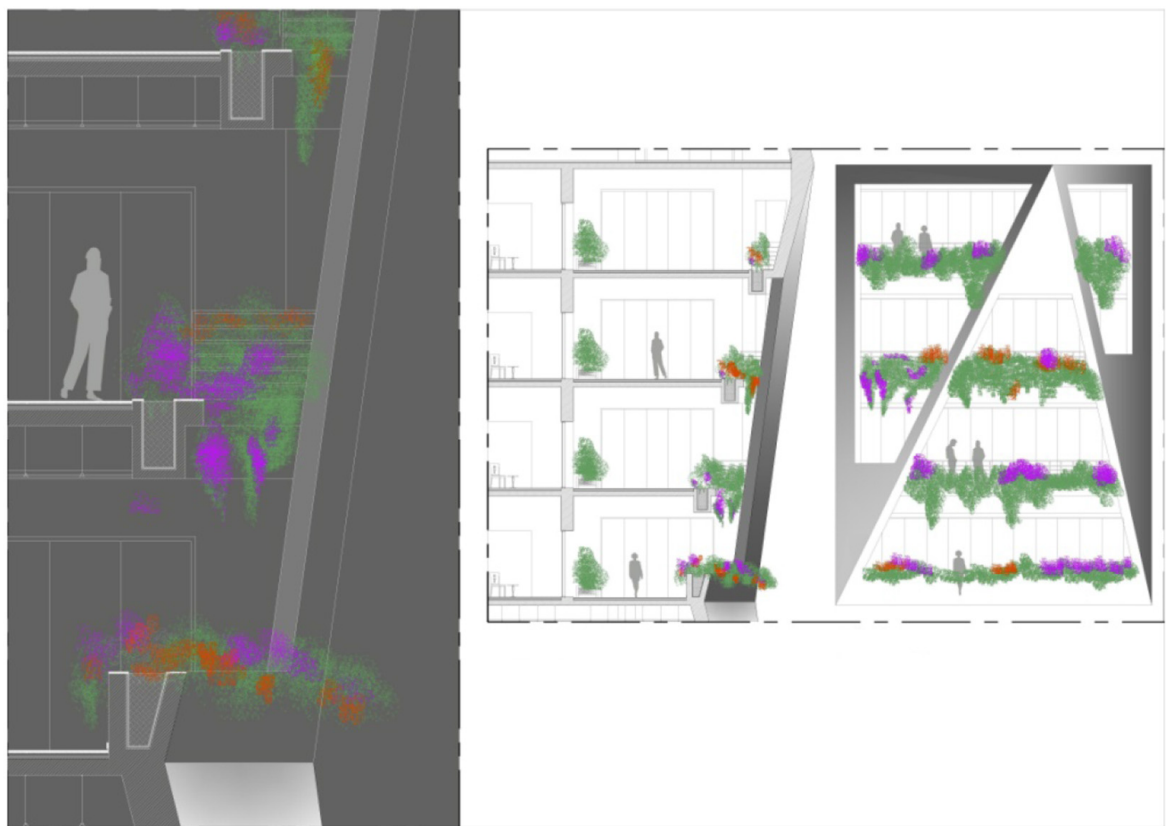

Figure 2: Section (not to scale) through Liwan terrace showing planters to grow organic food and contribute to the biophilic design of the apartment.

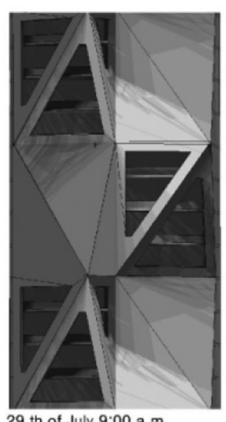

29 th of July 9:00 a.m.

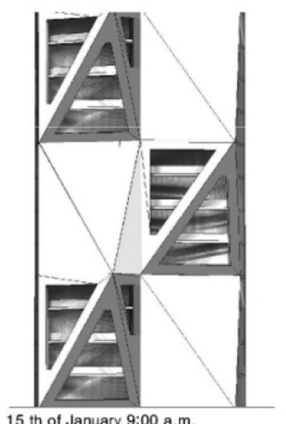

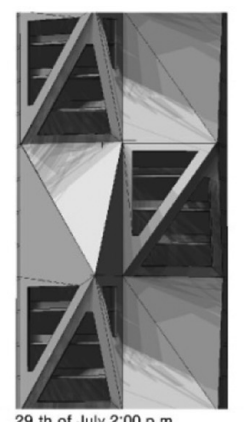

29 th of July 2:00 p.m.

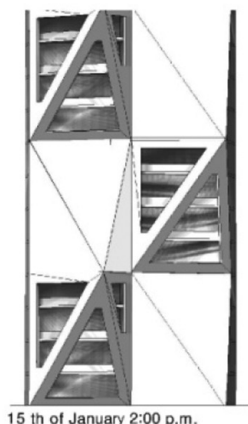

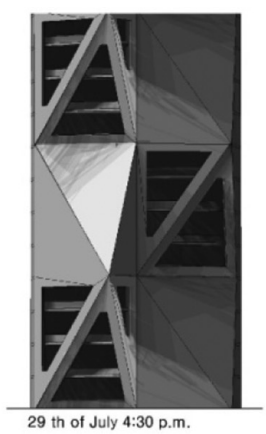

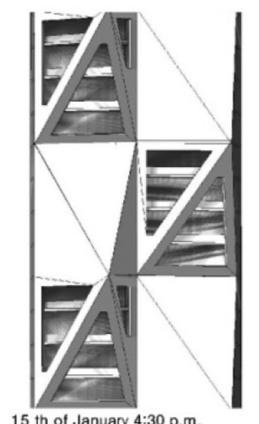

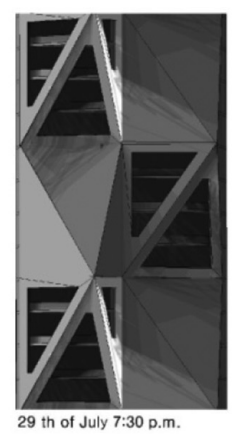

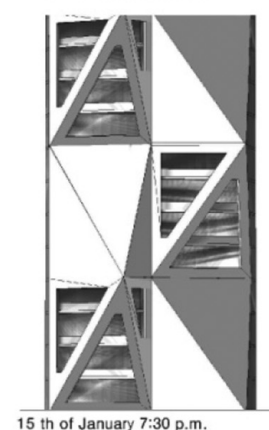

Figure 3: Shadow analysis on the south facade. 


\section{INTEGRATING RENEWABLE ENERGY WITH ARCHITECTURE}

Insolation analysis (Fig. 4) was performed on the same morphology to analyse the opaque facade components that best favour the use of building integrated photovoltaic panels (BIPV) and that does not receive any shading while receiving the highest average of direct solar radiation (more than 300 $\mathrm{W} / \mathrm{m}^{2}$ ). A scenario was chosen where the total surface of BIPV panels is about $400 \mathrm{~m}^{2}$; however, this surface may be increased if the remaining opaque surface were also mounted by PV panels. Overcoming the restriction of using PV panels only on regular rectangular or squared shapes, many manufacturers are integrating the PV panels on irregular shapes where the residue space not accommodating the regular measures of the PV panels is covered by a customized 'dummy' panel that has the same look as the rest of the BIPV surface.

\section{CONCLUSION}

In this paper, I have demonstrated through an applied design that I referred to by the term 'experiment' how an unselfconscious design of Liwan house may be profitably used in the self-conscious design (BSRP) of a modern high-rise residential building. The neurological basis of design proves that cognitive understanding of the environmental and cultural characteristic of the unselfconscious design stimulates the neocortex of the brain, thus resulting in a boost of pleasant effect. The continuous human hunger for information must be directed towards the natural world and natural lifecycles to create sustainable designs that interact symbiotically with the environment; furthermore, I have demonstrated how technological innovation may be interwoven aesthetically with the architectural structure. Eventually, I hope that my proposed experiment (Fig. 5) and this paper would promote awareness of how important it is to apply lessons learned from traditional designs in our current practice not only to preserve the environment but also to preserve a culture that is losing identity; a call to all designers and architects is urgently needed to work compatibly with natural resources and biological perceptions.
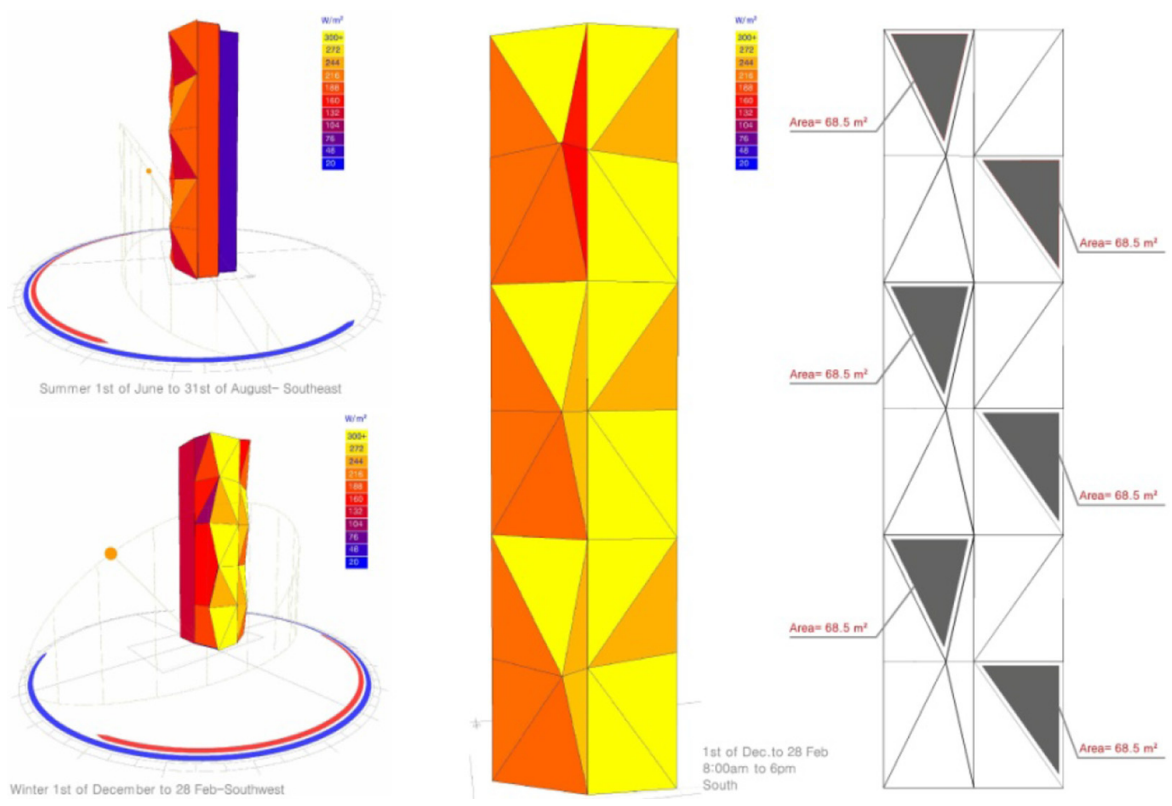

Figure 4: Insolation analysis and surface of PV panels. 


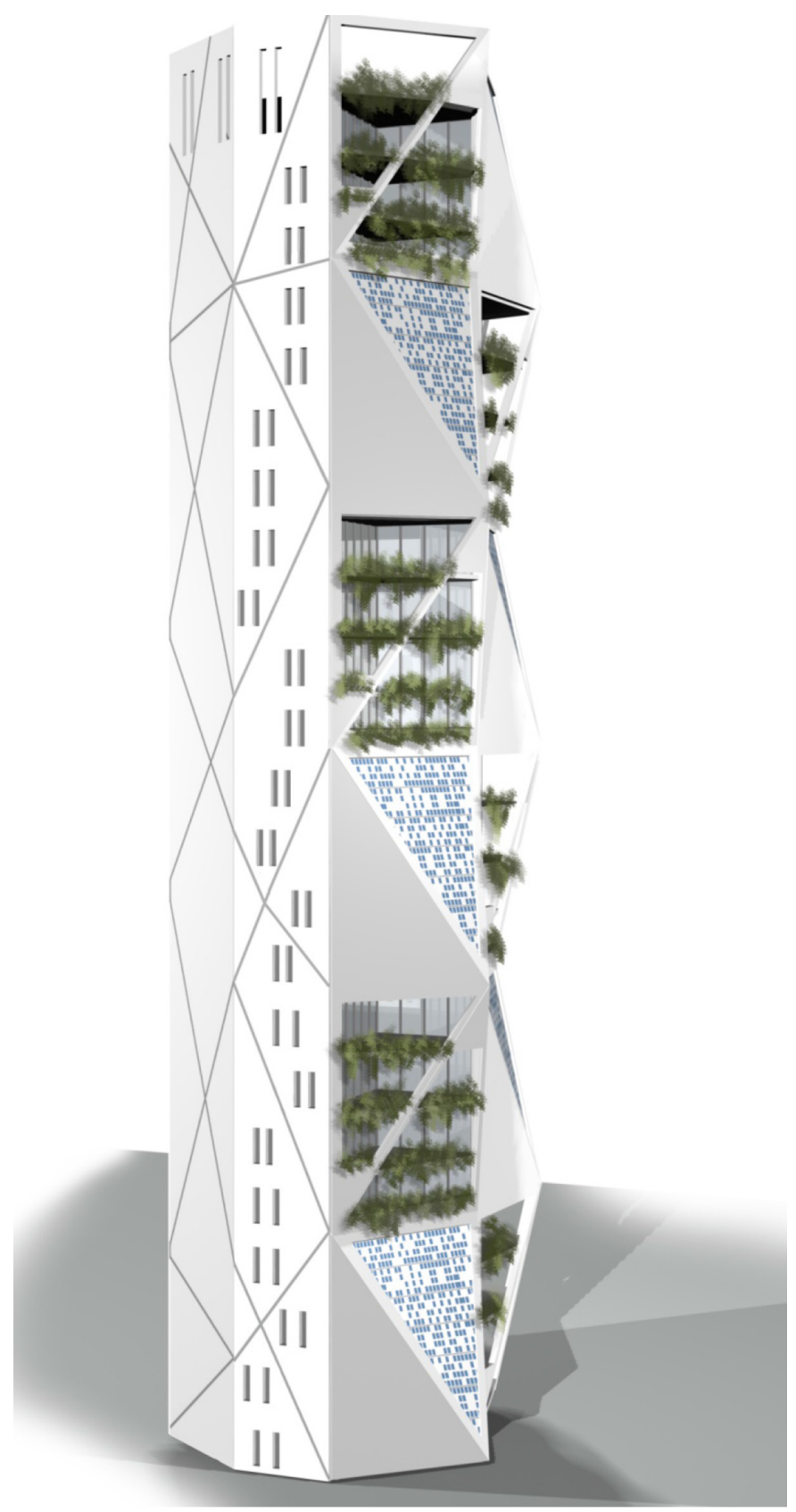

Figure 5: South-west view of Beirut Residential Sustainable Prototype. 


\section{REFERENCES}

[1] Alexander, C., Notes on the Synthesis of Form, Harvard: Cambridge, 1964.

[2] Ashby, W.R., Design for a Brain, John Wiley \& Sons: New York, 1952.

[3] Biederman, I. \& Vessel, E.A., Perceptual pleasure and the brain. American Scientist, 94(3), p. 247, 2006. doi: http://dx.doi.org/10.1511/2006.59.995

[4] Dawkins, R., The Extended Phenotype, Oxford University Press: Oxford, 1989. doi: http:// dx.doi.org/10.1046/j.1420-9101.1991.4010161.x

[5] Bernard, C., Lectures on the Phenomena Common to Animals and Plants, Springfield: Illinois, 1974. doi: http://dx.doi.org/10.1017/s0033291700007716

[6] Liger-Belair, J. \& Kalayan, H.Y., L’Habitation Au Liban, Syco Publicité: Beirouth, 1966. 